STUDI

FRANCESI

\section{Studi Francesi}

Rivista quadrimestrale fondata da Franco Simone

174 (LVIII | III) | 2014

Varia

\title{
Aa. Vv., "Le Rouge et le Noir" de Stendhal. Lectures critiques, sous la direction de Martine Reid
}

\section{Michel Arrous}

\section{(2) OpenEdition}

1 Journals

\section{Édition électronique}

URL : http://journals.openedition.org/studifrancesi/1541

DOI : 10.4000/studifrancesi. 1541

ISSN : 2421-5856

Éditeur

Rosenberg \& Sellier

\section{Édition imprimée}

Date de publication : 1 novembre 2014

Pagination : 612-613

ISSN : 0039-2944

\section{Référence électronique}

Michel Arrous, " Aa. Vv., "Le Rouge et le Noir" de Stendhal. Lectures critiques, sous la direction de Martine Reid », Studi Francesi [En ligne], 174 (LVIII | III) | 2014, mis en ligne le 01 novembre 2014, consulté le 18 septembre 2020. URL : http://journals.openedition.org/studifrancesi/1541; DOI : https://doi.org/ 10.4000/studifrancesi. 1541

Ce document a été généré automatiquement le 18 septembre 2020.

\section{(c)}

Studi Francesi è distribuita con Licenza Creative Commons Attribuzione - Non commerciale - Non opere derivate 4.0 Internazionale. 


\title{
Aa. Vv., "Le Rouge et le Noir" de Stendhal. Lectures critiques, sous la direction de Martine Reid
}

\author{
Michel Arrous
}

\section{RÉFÉRENCE}

AA. VV. "Le Rouge et le Noir" de Stendhal. Lectures critiques, sous la direction de Martine REID, Paris, Classiques Garnier, 2013, pp. 243.

1 La «Chronique de 1830» figurant au programme de l'agrégation de lettres, Martine REID a proposé de la relire, non seulement à des spécialistes de littérature, mais aussi à des historiens du livre, de l'art, du fait religieux ou du cinéma. D’où quelques dissonances dans cet ensemble de contributions venues d'horizons différents et classées en trois sections: «Le livre, la presse», «Questions de forme», «Savoirs et représentations». Avec l'éditrice qui juge l'ensemble «parfois discordant», on peut espérer que cette relecture offrira des surprises.

2 En ouverture, l'historien du livre Bruno BLASSELLE rappelle quelques faits connus qui permettent de situer la publication du Rouge, au moment où l'augmentation régulière de la production de livres subit un violent coup d'arrêt (Le livre en 1830. Un monde en mutation, pp. 17-32). Alors quasiment parisienne, l'édition est contrôlée par Ladvocat, Gosselin, Canel, Barba, Didot, Bossange et l'entreprenant Levavasseur qui édita le roman de Stendhal. Si Le Rouge ne fut pas un véritable succès de librairie, il eut au moins le mérite de retarder la chute de son éditeur! La proximité entre le roman de Stendhal et la presse a été souvent soulignée, aussi Marie-Ève THERENTY a-t-elle choisi de l'illustrer en étudiant l'intertexte que constituent les fameux «journaux carrés», plus précisément «Le Figaro». Bien que «hanté par le journal», Le Rouge, à la différence des nombreux romans d'actualité, n'est pas le «roman du journaliste», car Stendhal se 
garde de recopier le journal (Hypotextes, architextes et augures. Le feuilleté médiatique dans "Le Rouge et le Noir", pp. 33-50).

3 Retour à l'inévitable débat sur le réalisme avec les questions de forme. Andrea DEL LUNGO (Entrer en Stendhalie. Sur l'incipit du "Rouge et le Noir", pp. 53-65) propose une analyse fonctionnelle et herméneutique du premier chapitre qui met en évidence le procédé de la «focalisation omnisciente»: le voyageur-narrateur produit un discours critique sur la «petite ville». C'est le côté incertain et inquiétant des enjeux politiques et sociaux à la veille de 1830 que Peter BROOKS envisage dans Note secrète et coup de pistolet (pp. 67-78). Susanna LEE (Le hasard, la providence et le monde laï, pp. 79-98) traite de la subversion ironique à l'œuvre dans un roman qui met en cause les forces externes, celles de la machine sociale, dont dépendent ou non les personnages. Pour autant, peut-on accorder au hasard le rôle d'une cause première? Dans la carrière de Julien et tout au long de son apprentissage social, David J. BeLl constate que le tact de Stendhal joue un rôle fondamental (pp. 99-114), aussi bien chez les personnages que chez le romancier soucieux à la fois de réduire les disparates et, plus encore, de manipuler ou de piéger son lecteur.

4 Jérôme LAURENT consacre une étude pertinente («Lire la physionomie» selon Stendhal, pp. 117-133), à la phénoménologie des passions. Stendhal pratique l'analyse psychologique et sociale à partir de ce qu'il appelle «le langage des signes», par exemple le langage sans paroles des larmes ou celui du corps qui n'est d'ailleurs jamais saisi dans sa totalité. S'il a pu passer pour un lavatérien convaincu, il préfère la physionomie à la physiognomonie. Martine REID (Représentation de la différence sexuelle, pp. 135-153) délaisse un instant la figure héroïque du beau Julien pour interroger l'identité féminine, plus exactement sa représentation avec, d'un côté, le féminin convenu de Mme de Rênal, de l'autre sa version romanesque chez Mathilde finalement «domptée» par Julien, lequel lui préférera «un féminin parfaitement dépendant et dont on dépend parfaitement». Dans sa représentation de la femme "en deux volumes», Stendhal se montre donc conservateur, «prisonnier de ses lectures et de ses propres a priori». Quant au héros, son identité pose problème tant sont nombreuses ses contradictions, qu'il abolira selon un scénario où se retrouverait l'investissement libidinal de l'auteur. Le Conservateur en chef du patrimoine qu'est Emmanuel SCHWARTZ (La matière du pittoresque stendhalien. Le jeu des arts et des lettres, pp. 155-172) jette de trop rapides coups de sonde qui renseignent un peu au hasard, notamment sur le gothique en 1830. Que l'auteur du Rouge n'ait jamais mis les pieds dans un séminaire ni connu la vie sacerdotale ou les préoccupations épiscopales, nul n'en doute. Aussi ne doit-on pas s'étonner que NadineJosette CHALINE, spécialiste d'histoire religieuse, émette force réserves quant à la connaissance que le «libéral» Stendhal pouvait avoir des réalités de la vie de l'Église ("Le Rouge et le Noir". Une image du clergé et de l'Église en ce premier tiers du XIXe siècle?, pp. 173-188). Ann JEFFERSON adopte une autre démarche, plus significative parce qu'elle rapproche sans les confondre le romancier de l'historien. En s'intéressant aux comportements vestimentaires - et non pas au vêtement en soi - Stendhal témoigne de la culture matérielle et surtout d'une politique des apparences (L'uniforme du siècle en 1830, pp. 189-204).

5 À ces nouvelles perspectives qui ont le mérite de relancer les débats ou d'en ouvrir de nouveaux, s'ajoute un brillant exposé, par Laurent JULLIEN et Guillaume soulEz, des partis-pris de la première adaptation du roman à l'écran (Coda. Tableau, élan, film. "Le Rouge et le Noir" de Claude Autant-Lara (1954), pp. 205-228). 